\title{
A Study on Influencing Factors of College Students' Compliance to Strangers' Requests
}

\author{
Zonghe Zhang ${ }^{1 *}$ Dan Kuai ${ }^{2}$ Lu Zhang ${ }^{3}$ \\ ${ }^{1}$ New Media Research Center, Nanfang College of Sun Yat-Sen University, Guangzhou, Guangdong, 510970, China \\ ${ }^{2}$ School of Civil Engineering, Wuhan University, Wuhan, Hubei, 430072, China \\ ${ }^{3}$ Guangzhou Rural Commercial Bank, Guangzhou, Guangdong, 510970, China \\ * Corresponding Author. Email: zonghe.zhang@outlook.com
}

\begin{abstract}
In our daily life, we often encounter requests from strangers. What are the factors that affect our decisions to obey or refuse? Taking college students as the research object, using the Big Five Personality Questionnaire, Compliance Behavior Scale (GCS) and the self-compiled college students' compliance behavior influencing factors questionnaire as research tools, this paper studies the influencing factors of compliance when facing strangers' requests. Through research, we found many factors that affect college students' compliance behavior when facing strangers' requests. This research summarized them as: requestor factor, respondent factor and environmental factor.
\end{abstract}

Keywords: compliance behavior, stranger's request, influencing factors of compliance

\section{INTRODUCTION}

The phenomenon that an individual obeys others' domination in behavior and accepts others' command is called compliance [1], which is the tendency of an individual to act according to others' opinions, requests or instructions for some reasons. It has two main components: the desire to seek pleasure and the need to maintain selfesteem when others are present, and the need to avoid conflicts and keep in line with others, especially when the other party is authoritative in some aspect [2].

What causes us to accept strangers' requests without thinking? According to previous studies, many factors on the requestor will affect our compliance behavior, such as skilled request [3], polite expression [4], positive emotion [5], and seemingly high authority [6] of the requestor will promote compliance, and the individual characteristics of the requestor [7] will affect the compliance of the requested person. On the other hand, the requested person's personality traits [8-9], self-esteem and anxiety level [2] and other factors will affect compliance behavior. In addition, situational factors will have an impact on the compliance behavior in the face of strangers' requests. Seeking pleasure in the presence of others and maintaining self-esteem, avoiding conflicts and being consistent with others are the main components of compliance [10].

Previous studies have mainly focused on influential factors of compliance, but have not studied the systematic influential factors of compliance of college students when facing requests from strangers. In this study, college students are taken as the research object to study the influencing factors of college students' compliance when facing strangers' requests. This is of great significance for us to make more rational decisions when facing strangers' request situations, to really choose good deeds and to reduce the manipulation of us by people with ulterior motives.

\section{STUDY DESIGN}

In this study, a total of 400 questionnaires were distributed to college students. After recovery, the invalid questionnaires were eliminated, leaving 368 valid questionnaires, with an effective recovery rate of $92 \%$. The research tools are as follows:

The personality was measured by the "Big Five Personality 40 Edition Concise Questionnaire" [11]. The questionnaire has good reliability and validity. The retest coefficient is between 0.67 and 0.81 , and the average retest coefficient is 0.74 .

Compliance was measured by the Compliance Behavior Scale (GCS) developed by British professor Gudjonsson [12]. In order to ensure the scientificity and objectivity of the research, the translated scale was first analyzed by items and tested for reliability and validity before it is officially used. After project analysis, the items that do not meet the discrimination requirements are deleted, leaving 19 items. The internal consistency reliability of the scale is 0.68 , with good reliability. After exploratory factor analysis, three factors were obtained, which can explain $54.3 \%$ of the total variance and have good structural validity.

The Questionnaire on Influencing Factors of College Students' Compliance Behavior was compiled by combing and analyzing the interview results of college students, with a total of 22 items. 


\section{RESEARCH RESULT}

\subsection{Influence of Requestor Factors on Compliance}

From Table 1, we can see that the requestor factors are classified into two categories: trait factors and skill factors. Among the trait factors, gender and college students' compliance behavior in the face of strangers' requests are independent of each other, that is, the requestor's gender has no significant influence on college students' compliance, while other requestor trait factors such as attractiveness have significant influence on college students' compliance. The concrete manifestation is that the better the appearance, the higher the charm, the gentler the tone and the more polite of the requester, the higher the probability of compliance of college students.

As for the skill factors of the requestor, except 'give praise to the requested or not' has no significant effect on the compliance of college students, other factors have significant effect on the compliance of college students. The concrete manifestation is that the higher the degree that the requester shows that he needs help and the more novel the request method is, the more times the request is made, the higher the probability that the compliance behavior of college students will occur. Moreover, when the requestor interprets the request, it will make people take more compliant behaviors than when they do not interpret the request.

Table 1. Analysis of the Influence of Requestor Factors on Compliance

\begin{tabular}{|c|c|c|c|c|}
\hline \multicolumn{2}{|r|}{ Requester Factors } & $x 2$ & $d f$ & $p$ \\
\hline \multirow{4}{*}{ Trait factors } & Gender & 1.56 & 1 & 0.21 \\
\hline & Charm & $21.92 * *$ & 4 & 0.00 \\
\hline & Polite or not & $50.08 * *$ & 4 & 0.00 \\
\hline & Tone & $41.22 * *$ & 4 & 0.00 \\
\hline \multirow{5}{*}{ Skill factor } & Explain or not & $1.891 *$ & 4 & 0.04 \\
\hline & Number of requests & $68.57 * *$ & 2 & 0.00 \\
\hline & Show a degree of need for help & $84.39 * *$ & 4 & 0.00 \\
\hline & Give praise or not & 8.97 & 4 & 0.06 \\
\hline & Novelty of Request Method & $16.24 * *$ & 4 & 0.00 \\
\hline
\end{tabular}

\subsection{The Influence of College Students' Own Factors on Their Compliance}

\author{
3.2.1. Relationship between personality and \\ compliance
}

Table 2 shows that compliance is positively correlated with neuroticism and agreeableness, while openness, extroversion and rigorous are negatively correlated. This shows that individuals with higher neuroticism level and higher agreeableness level have higher compliance, while those with higher openness, extroversion and rigorous have lower compliance in the face of strangers' requests.

Table 2. Analysis of the correlation between personality types and compliance

\begin{tabular}{|c|c|c|c|c|}
\hline & Neurotic & Rigorous & Openness & Extroversion \\
\hline Compliance & $0.31^{* *}$ & $-0.12^{*}$ & $-0.21^{* *}$ & $-0.13^{*}$ \\
\hline
\end{tabular}




\subsubsection{Relationship between factors of college students and compliance}

Table 3 Chi-square test on the influence of the respondent's own factors on compliance shows that six factors, such as gender, grade, major type, school type, only child or not, and time urgency, are independent of compliance, and have no significant influence on the compliance of college students when facing strangers' requests.

The four factors of college students' emotional state, empathy, sense of embarrassment and whether they have similar experiences have a significant impact on compliance.
According to the results, the better the emotional state of college students, the higher the level of sympathy for the requestor, the higher the shame of refusing the request, and the similar experience, the higher the compliance of college students, the more likely they are to accept the requests.

Among them, compliance is positively correlated with neuroticism and agreeableness, while openness, extroversion and rigorous are negatively correlated. This shows that individuals with higher neuroticism level and higher agreeableness level will have higher compliance in the face of strangers' requests, while those with higher openness, extroversion and strictness will have lower compliance in the face of strangers' requests.

Table 3. Analysis of the influence of the respondent's own factors on compliance

\begin{tabular}{|c|c|c|c|}
\hline Respondent's own factors & $\chi^{2}$ & $\boldsymbol{d f}$ & $\boldsymbol{p}$ \\
\hline Gender & 0.28 & 1 & 0.60 \\
\hline Professional type & 5.67 & 4 & 0.23 \\
\hline Grade & 4.23 & 7 & 0.75 \\
\hline Types of school & 0.02 & 1 & 0.89 \\
\hline Only child or not & 0.01 & 1 & 0.97 \\
\hline Time urgency & 8.45 & 5 & 0.13 \\
\hline Emotional state & $34.06^{* *}$ & 4 & 0.00 \\
\hline Same emotion & $28.61^{* *}$ & 4 & 0.00 \\
\hline Embarrassed & $16.57^{* *}$ & 4 & 0.00 \\
\hline Similar experiences & $9.72^{* *}$ & 1 & 0.00 \\
\hline
\end{tabular}

\subsection{Influence of Situational Factors on Compliance}

Table 4 shows that when faced with the same request, when there are other people around who are willing to help, the requested person will tend to grant the request of the stranger. When most of the people around you obey, the requested college students have the highest compliance, and when most of the people around you refuse, their compliance is the lowest. The more difficult the content requested by strangers is to complete, the less likely people are to show compliance. When strangers give reciprocity to the requested person, such as giving small gifts, the probability of people's compliance is much greater than that without reciprocity. 
Table 4. Analysis of the impact of situational factors on compliance

\begin{tabular}{|c|c|c|c|}
\hline Situational Factors & $\boldsymbol{\chi}^{2}$ & $\boldsymbol{d f}$ & $\boldsymbol{p}$ \\
\hline Number of People around & $8.15^{*}$ & 3 & 0.04 \\
\hline The performance of others & $26.24^{* *}$ & 2 & 0.00 \\
\hline Request event completion difficulty & $31.1^{* *}$ & 4 & 0.00 \\
\hline Give or not give reciprocity & $27.87^{* *}$ & 1 & \\
\hline
\end{tabular}

\section{DISCUSSION}

In the face of strangers' requests, college students' compliance behavior is affected by many factors. This study summarizes them into three categories: requester factor, requested factor and situational factor.

As for the requestor factor, the study found that college students are more likely to follow attractive and skilled people when facing the requests of strangers.

Some characteristics of college students themselves, as well as emotional state and experience, will affect our compliance in the face of strangers' requests. Don't miss the chance to help people who really need help because of your own characteristics, nor will you be used by people with ulterior motives because of your own characteristics. This is the place where rational handling is needed.

The study found that situational factors such as the number of people around and whether the requestor provided reciprocity also had a great impact on college students when they faced strangers' requests.

Generally speaking, college students should consider rationally before accepting the requests of strangers. Whether the decision to grant a stranger's request is based on rational considerations or passive compliance under the influence of the requester's factors, self-factors and environmental factors. The state we are pursuing should be to try our best not to miss helping a person who really needs help, nor to be used, encroached on or even hurt by any ulterior motives who know how to influence others' compliance.

\section{REFERENCES}

[1] Lin Chong-de, Yang Zhiliang, Huang Xiting. A Dictionary of Psychology. Shanghai: Shanghai Education Press, 2003:1179.

[2] Gislih .Gudjonsson ,Jon fridrik Sigurdssson . Compliance and Personality: The Vulnerability of the Unstable Introvert European [J]. Journal of Personality ,2004:435-443
[3] Guéguen Nicolas. Handshaking and Compliance with a Request: A Door-to-Door Setting [J]. Social Behavior and Personality ,2013,41(10):1585-1588.

[4] Aaron J.Vaughn Michael W.Firmin and Chi-en. Hwang. Efficacy of request presentation on compliance [J]. Social Behavior \& Personality,2009,37:441-449.

[5] Wang Xinjian. Advanced Course in Social Psychology. Hefei: Anhui People's Publishing House, 2011:121-125

[6] Robert B. Cialdini and Noah J. Goldstein. Social Influence: Compliance and Conformity [J]. Annual Review of Psychology, 1998, 55: 591-621

[7] Sun Ye, Li Yi. Social Psychology. Beijing: Science Press, 1988: 98-110.

[8] Gudjonsson, Gisli H. Personal versus impersonal relationship compliance and their relationship with personality $[\mathrm{J}]$. Journal of Forensic Psychiatry \& Psychology, 2008,19(4): 502-516.

[9] Xiaohua Chen,Natalie H. H. Huia \& Michael Harris Bond. Reexamining Personal, Social, and Cultural Influences on Compliance Behavior in the United States,Poland,and Hong Kon [J]. The Journal of Social Psychology ,2010,7:223-244.

[10] Gislih. Gudjonsson, Jon fridrik Sigurdssson. The relationship of compliance with anxiety,selfesteem,paranoid thinking and anger[J]. Psychology Crime \& Law,2002,8(2):145-153.

[11] WANG Meng-Cheng, DAI Xiao-yang, YAO Shuqiao. Development of the Chinese Big Five Personality Inventory (CBF-P) III: Psychometric Properties of CBF-PI Brief Version[J]. Chinese Journal of Clinical Psychology, 2011, 19(04): 454-457.

[12]Gudjonsson.Compliance In An Interrogative Situation - A New Scale [J].Personality and Individual Differences, 1989,10(5): 535-540. 